\section{ATOMS AND MOLECULES*}

THE atomic composition of ponderable matter is a fundamental postulate in the theory of chemical equivalency. By the application of the principles of experimental research, and by methods essentially modern, resulting in the discovery of many elementary bodies and their modes of combination, a conception of very great antiquity has been rendered more distinct and worthy of credence. When this conception took definite form is not known. Indeed, it is one of the many speculations naturally elicited in discussing those subtle questions pertaining to the existence of matter and its relations to mind or spirit, the solution of which has always baffled, and will continue to baffle, the most profound thinkers. In attempting to unfold the mysteries of nature by the deductive process, the ancient reachers of Cosmogo.zy were brought into direct conflict of opinion regarding the ultimate condition of matter. That it is composed of indestructible atoms which admit of no division, seems to have been the notion of some Oriental sages. Under the genius of the Greek philosophy this notion assumed the form and consistency of a theory.

Among those who held the doctrine, while immatured, were Ecphantus, Leucippus, and Democritus. Subsequently Epicurus introduced such modifications and improvements as were essentia to its complete development. $\dagger$ The Latin poet Lucretius, in his "De Rerum Naturâ," has given a full exposition of the Epicurean philosophy; from this, as well as from the writings of Plutarch, it will be seen that the most prominent atomic tenets did not differ essentially from the opinions entertained by eminen scientists of modern times. \pm Newton admitted the creation of primitive particles, extremely minute, but permanent. Descartes, on the other hand, held with Aristotle, Plato, and Pythagorae that the division of matter has no assignable limit. Leibjitz attempted to reconcile the conflicting opinions of metaphysicians and mathematicians, by supposing that matter, in its ultimate condition, consists of unextended points which he denominated monads, a term borrowed from Pythagoras. At a later day, Boscovich published his celebrated dynamic theory, in which centres of force are substituted for monads. Neither of these ingenious theories however, reaches the real points of perplexity.

It is obvious that the science which treats of the ultimate composition of bodies would lead to more correct conceptions regarding minute combinations of ponderable matter. Analysis has slown that nearly all the bodies formed in the great laboratory of nature are compounds. Thus far, sixty-three different kinds of matter have resisted every effort to resolve them into simpler constituents. These substances, distinguished as chemical ele ments, unite in exceedingly minute quantities according to ths well-known laws of Stoichiometry. In the year $\times 789$, Higgins, a professor in the University of Dublin, advanced the idea that certain compounds are formed by the combination of ultimate particles or atoms of different elements. Dalton, in 1803 , in dependently araived at a similar conclusion, which he generalised, to explain the composition of all compounds, and made it the basis of his " New System of Chemical Philosophy," published five years later. The doctrine of Dalton has undergone, since his day, such modifications as render it more acceptable; but that part of it which ascribes the union of indestructible atoms to chemical affinity may be regarded as the first successful attempt to explain that primordial action which the ancient atomists could

* Reprinted from the American Chemist, corrected by the author.

* Reprinted from the American Che morals." Edited by Prof. Goodwin, of Harvard Univer. $\dagger$ Plutarch's “Morals.” Edited by Prof. Goodwin, of Harvard Univer.
sity. (Little, Brown, and Co., Boston, Mass.) Vol. viii. pp, ir I-riz. Vol. v. p. 345 .

I. A full exposition of the ancient atomic philosophy would be foreign to the purpose of this paper. Many of the prevailing erroneous impressions concerning it would, however, be corrected by an examination of the third chapter of Dr. Good's "Book of Nature, in which Epicurus is ably defended against the charge of atheism. Evidently the Epicureans were op posed to Mythology; but while ignoring the power of its gods, they were naturally led to the recognition of a higher Power, an Intelligent Cause, Self existent, and Supreme. This deduction was reached by the earnest believer in the atomic doctrine. According to Stobzus, Ecphantus supposed the material world to consist of atoms, but yet to be ordered and governed by a

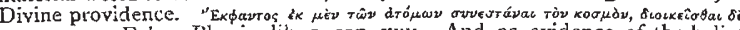

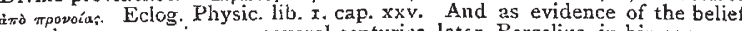
prevalent among wise men several centuries later, Berzelius, in his paper on "Proportions, determinate," quotes from Philo, who, in his collection of the choicest philosophical ideas of his time (" Libri Sapientiæ," cap. xi. v. 22),

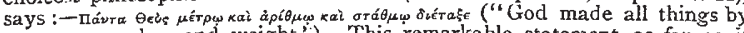
measure, number, and weight'). 'This remarkable statement, as far as it relates to things terrestrial, modern chemical investigations have fully confirmed. not account for, and which the Latin poet above named describes as irregular and fortuitous. *

Chemists of the atomic school happily avoid the vexed question concerning the indivisibility of matter, by defining an atom as the smailest quantity of an element which can enter into the composition of a ponderable molecule; and the molecule, whe. the: made up of one, two, or more elements, as the smallest quantity which can exist in a free state. However, a certain individuality must be assigned to the single atom, for a chemical decomposition requiring its transfer from one molecule to another involves its isolation in transitu. The absolute weight of the sixty-three different atoms cannot be ascertained; nevertheless, their relative weights have been determined with great care.

It is difficult to arrive at any clear notions concerning the size of an object so minute as to be for ever invisible under the most powerful magnifier. As an example of the conclusions regarding molecules, founded on microscopic scrutiny, that of the celebrated Ehrenberg may be cited. $\dagger$ Without attempting to make a close approximation towards its actual dimensions, his researches led him to infer that the diameter of an atom (the molecule of the chemist) was considerably less than six millionths of a line. Quite recently Sir W. Thomson, in a paper "On the Size of Atoms," $\ddagger$ presented four lines of argument founded on experiments of physicists, which all lead to substantially the same estimate of the dimensions of molecular structure. $\mathrm{He}$ says :-

"Jointly they establish, with what we cannot but regard as a very high degree of probability, the conclusion that, in any ordinary liquid, transparent solid, or seemingly opaque solid, the mean distance between the centres of contiguous molecules is less than the hundred-millionth and greater than the two thousand. millionth of a centimetre. To form some conception of the degree of cross-grainedness indicated by this conclusion, imagine a rain-drop, or a globe of glass as large as a pea, to be magnified up to the size of the earth, each constituent molecule being magnified in the same proportion. The magnified structure would be coarser grained than a heap of small shot, but probably less coarse grained than a heap of cricket balls."

From these deductions of Thomson sone idea may be formed of minute molecular grouping; and I venture the suggestion that, in regard to size, the smallest bullet would probably stand about mid-way between the glomeranen minimum and "the great globe itself."

Beyond this point of extreme tenuity, where matter first exhibits that property which is revealed in visible forms, we are forced to consider it in a still more expanded state, as the universally diffused medium of light, heat, and actinism; consequently this conception of the minute ponderable globule does not bring us very near the minima nature, for a difference in size cannot be less marked between ponderable atoms and those in. finitesimal particles forming the luminiferous ether or æeth which fills the interstellar spaces, and which, in a more condensed state, probably forms the interatomic medium. Assuming that all forces generating wave motions in elastic fluids follow the same law of propagation, I endeavoured some years ago to estimate the density of this inconceivably attenuated substance. $\$$

In that calculation the density of air is the unit of measure. If instead hydrogen be taken as the unit, the density of luminiferous ether is expressed by the decimal 00000000001653 . Whatever may be its actual density, its reality must be admitted, until the positions established by the investigations of Huyghens,

Omnimodis coire, atque omnia pertentare,

Quæcunque inter se possint congressa creare

Pogg. Annalen. xxiv., 35. Itcret. lib. v. ver. I9I.

$\$$ Sound would be propagated, with exactly the velocity of light through a fluid, under the standard pressure, $874,094,104.900$ times rarer thau Therefore, if the density of air be $\mathrm{I}$, the density of 2 th is represented by the decimal $000,000,000,0 \mathrm{r}, \mathrm{I} 41+$.

It will not be inferted from this view that the aim has been to reach "The first of things, quintessence pure,"

for the elastic quality of rth involves the hypothesis of a still more subtle fuid. We have raised one curtain only to find another to be raised. As the unfathomed vaults of Heaven recede before the sweep of a more powerful refractor, and nebula resolved reveal nebulz beyond, so the most diminutive germ that springs from the Creator's touch discloses through the lens of higher pownr new signs of more wonderful mechanism within. Each nucleus has its nuclei! Each entoblast is but the boundary of a microcosin! Each particie a galaxy of atoms revolving in the all-pervading ath! Thus, before every far-reaching human advance, Circumference and Centre will for ever retreat...Transactions of the Anerican Institute, 2864, p. 539. " Clydonics," No, I) 
Young, Fresnel, Foucault, and Fizeau, are shown to be untenable. A very able American metaphysician, in meeting an objection brought by Huxley against the views of Comte, has strongly expressed his unqualified dissent ; ${ }^{*}$ nevertheless, the hypothesis that light, heat, and ac'inism are propagated by the undulations of a subtle all-pervading fluid, is the only one which satisfactorily accounts for a certain class of phenomena, and it is accepted by all the prominent experimental physicists of the present day.

The vast difference in density indicated cannot be apprehended, because numerical eomparisons utterly fail to raise in the mind any clear conception regarding a fluid so attenuated; yet it naturally suggests the idea that there must be many intervening conditions of matter in which it exists in successive degrees of increasing density, and that these conditions form the connecting links, so to speak, between its apparently imponderable and its ponderable states. Something like this opinion seems to have been maintained in a curious work published in England many years ago.t The reverend author, viewing the universe as a systematic manifestation of the Divine Will, assumes that the medium of light is the mother element from which by progressive steps the chemical elements have been evolved. Proceeding from the first lines of morpholory he arrives at the primitive form which cannot be isolated; then by an exceedingly ingenious synthetic process he represents by diagrams his ideal structure of different kinds of atoms, all of which are duplicitions of the tetrahedron. Thus he claims to reveal the unit, by multiples of which the atomic weight of all chemiral elements may $b:$ expressed, and so arrives at a result which will be recog. nised as simply a modification of the s.-called law of Prout. Although this, and other remarkable surmises by Macvicar are, for reasons which need not here be adduced, quite untenable, he seems to have led the way to an assumption which has recently met with some favour, namely, that the chemical atom, although indivisible, is a collection of smiller particles. However, in following this author towards the infinitesimal, we only realise more fully the truth that above and below the narrow zone of the visible are objects too far off and too fine for human scrutiny. Although the scening all is rounded by intimation of other and brighter regions, Science can never compass them by any extension of her domain! In those unsounded depths which form the boundary and background of the known, thought grown dizzy finds no support; and even the positivist turns back bewildered when mensuration fails and computations end in surds!

On examining the numerous works on chemistry published within the last twenty years, one cannot fail to notice a gradual change in the expressions employed in describing reactions. The word "equivalent" seems to have lost the meaning originally assigned to it by Wollaston, and the terms "combining weight" and "combining proportion" are now used less frequently than "atomic weight" and "atom." This abandonment of old forms of expression doubtless indicates a gradual change of opinion among leading chemists, a change which may be ascribed pirtly to an accumulation of facts tending to confirm the atomic theory, and, partly, to the promptings of that mysterious intuition which, overleaping the limits of logic, often arrives at correct conclusions even before their truth has been demonstrated.

During all the discussions on "atomicity" hardly a doubt has been raised as to the actual existence of the atom. It was not, therefore, surprising that the ehemical world received a sensible shock at the stand made by Brodie in $1868 . \mp$. However, a careful examination of his paper is likely to lead to the conclusion that the objections to the atomic theory therein enumerated are not more formidable than those which can be urged against his own ingenious, but complicated method of chemical operations. Precision in signs and definitions leads to exact results in the abstract, nevertheless a mathematical formula of ten requires modification to meet the varying conditions found in actual practice, and even then it only gives a near approximation to the truth.

Renewed attention to this subject was doubtless the means of drawing from the then President of the London Chemical Society a paper "on the Atomic Theory," which is generally regarded as the best exposition and defence of the doctrine yet made, and which may be consulted with profit by those desiring to obtain a

* Eleventh Harvard lecture, by Prof. John Fiske. Cambridge, Mass. $x 869$ $t$ "Elements of the Economy of

(London: Chapman and Hall.) r856.

By Prof. B. C. Brodie clear statement of the principal results of chemical research adduced for its confirmation."

A vigorous attack on the atomic theory has since been made by Mills, the real tendency of which is to raise doubts concerning the existence of matter itself. + He quotes with evident satisfaction from a work by Digby "on the nature of bodies" printed in 1645 , wherein quantity is defined " as but one whole that may indeed be cut into so many several parts; but those parts are really not there till by division they are parcelled out; and then the whole (out of which they are made) ceaseth to be any longer, and the parts succeed in lieu of it, and are every one of them new whole." From this statement proceeds a train of geometrical reasoning concerning extension and division which leads to the old dilemma rezarding finite and infinite indivisibles.

Fortunately a new science, unknown to Digby, has demonstrated that matter has other than mere physical properties which are so clear and well defined as to enable its votaries to determine the ultimate composition of all bodies. The chemist affirms that, however inclined we may be to regard a body as a whole, it is in fact composed of minute parts which may be separated, and that in the great majority of bodies, which are compounds, Nature has herself made divisions by incorporating unlike parts which may be replaced by other unlike parts. On questions relating to the actual size of these parts, their form, their structure, \&s, he makes no issue; he simply asserts that all these ultimate parts are permanent, and that those composed of the same kind of matter are i.tentical in size and structure. The limits proposed for this paper will permit elucidation of this point alone.

The clearest conception of molecules and atoms will be arrived at by examining the principal phenomena attending the mechanical mixture and final chemical union of the lightest and the heaviest of the simple gases. The electro-positive element, hydrogen, is a permanently elastic gas, having a relative clensity expressed by $I$. Its properties are in marked contrast with those of chlorine, a yellowish green gas, which may be condensed into a liquid, by a pressure of about four atmospheres. The density of this strong electro-negative element is 35.5 . If two vessels of equal capacity, filled with these gases respectively, be placed in the dark, one over the other, and a communication be opened between them, a mutual diffusion of the gases will commence, the relative velocity being inversely as the square root of their densities. The action continues untraversed by the force of gravitation until minute portions of hydrogen and chlorine are equally diffused throughout both receptacles. This phenomenon caunot be accounted fur, excepting on the supposition that minute parts of each gas have undergone complete isolation. If diffusion were effected only through a single stratum or extremely thin layer, it would be possible for two gaseous elements to retain their continuity by passing each other in intertwining streams, thus forming like threads, a warp and woof; but when diffusion is in every direction it is obvious that these elements must positively separate each other, and thus be divided into extremely diminutive bodies each of the same dimensions. Let $l$ represent the lighter gas, $d$ the denser, and $e$ the dimensions or size of each isolated portion, then $e l$ and $e d$ will denote the dissimilar parts of which the whole gaseous matter is composed. As the phenomenon of diffusion occurs under the conditions mentioned, whatever may be the quantity of gases employed, it follows that $e l$ and $e d$ are individual volumes or molecules, invariably of the same dimensions. This diffusion of gases may therefore be defined as the uniform intermingling of disimilar molecules.

If the molecules $e l$ and $e d$ thus commingled while in the dark be exposed to direct sunlight, an instantaneous and complete chemical combination occurs with explosive violence but without condensation; or if exposed to diffused daylight, the union of elements will be gradual and without explosion; the resulting compound in each case being hydrochloric acid gas.

The affinity or force of chemism is generated by the action of light on the coloured gas chlorine, which, by absorbing all the rays and transmitting only the yellowish green, acquires a power which seems to be expended by the union of that element with hydrogen. Early in the present "century M. Benard announced that the new properties acquired by chlorine on exposure to light were derived from the violet ray. In 1843 Draper proved by experiment the relative power of each ray in producing this

\footnotetext{
Soc. London, Atomic Theory."

By Prof. A. W. Williamson. Four. Chem. Soc. London, vol. xxii. p. 328

By Edmund J. Mills, D.Sc, Philosophica Magazine, vol. xlii. No. 278, p. 12 .
} 
change, the astinic rays being altogether the most effective. * Mr. E. Budde has recently described a remarkable experiment in this direction. He found that a differential thermometer filled with chlorine expanded about seven times more; in the violet than in the red ray of the solar spectrum; when the same thermomeier was flled with $\mathrm{CO}_{2}$ no action was noticed. $\dagger$

As the combination of hydrogen and chlorine is effected without change of volume, it is obvious that the mote:ule $c l$ does not unite with the molecule $e t$, forming a compound molecule el-cl. The conclusion is there ore unavoiduble that eich molecule has been divided into two equal parts, and that by affinicy, like parts have been separated, and unlike parts have been united. These parts are the smallest quantities that can be isolated, and are in fact the atoms recognised by the chemist. If this smallest combining proportion or atom be designated by $a$, the actual composition of the hylrugen molecule $e l$, weighing 2 , may be clearly represented by al-al (weight $I+x)$, and the chlorine molecule e.t weighing 72 , by aut al (weight $35^{\prime} 5+35 \cdot 5$ ). As the attraction of $a l$ to $a l$, and of $a d$ to $a d$ is, after exposure to light, less than of al to alt, there is an instantaneous chemical change by which one molecule of liydrogen and one molecule of chlorine are transformed into two moiecules of hydrochloric acid gas. This reaction is clearly indicated by the following equation $: a l-a l+a d-a d=a l a d+$ alad $=2$ alad

The symbols here used are intended to convey to the mind an idea of the relative size of combining parts, which is not so apparent when expressed as follows :-

$$
\mathrm{H}_{2}+\mathrm{Cl}_{2}=\mathrm{HCl}+\mathrm{HCl}=2 \mathrm{HCl} \text {. }
$$

From the simplest of molecular types we might proceed to the most complex; and, throughout, if we consider the combining proportion of each simple constituent as either a unit or a multiple of a unit, the composition of each molecule may be expressed by whole numbers. Thus having as many different kinds of units as there are elements, any true chemical combination may be symbolised by a combination of arithmetical ratios. 'This method, under the light of the atomic theory, clearly reveals the harmonic relations of molecular constituents, which, seen from the stand-point of percentage composition, appear unconnected and discordant.

It must be admitted that many of the reactions of well-known bodies have not yet been determined quantitatively; yet were they made out, we should not be able to demonstrate by experiment the truth of the atomic doctrine. It still remains a theory, in favour of which there are many facts and phenomena that collectively form an argument not easily to be outweighet. This evidence may be briefly summarised as follows :-

I. Atomic Weights. Elements combine in extremely minute parts, according to the law of definite and multiple proportions. The atomic weight of an element is either its equivalent weight or a multiple of ir, as such multiple cannot be divided by reactions, its weight must conform with the atom!c number. Whatever changes of position the combining weight of an element may undergo in a series of molecular metamorphoses, that is to say, however many times it may be displaced and replaced in chemical combinations, it invariably retains its characteristic weight. This invariability of weight is an essential property of the atom. 2. Atomic Volume. Gases unite in equal volumes or multiple volumes. If hydrogen be taken as unity, the density of each elementary gas is identical with the weight of its atom. The atomic volume, determined by dividing the atomic weight of a body by its specific gravity, has been the means of revealing many interesting relations among compounds of similar structure, and among many containing different components and of unlike structure.

3. Atomic Heat. It has been shown by experiment that quantities of each element conforming with its atomic number have the same capacity for heat, excepting only carbon, boron, and silicon ; these, it is believed, will yet be found to conform to the law, that the specific heats of atoms are the same. This law is regarded as a direct confirmation of atomic weights.

4. Molecules. According to the atomic theory chemical forces are brought in equilibrium when atoms combine and form a molecule. Every gas and every vapour undecomposed has a density proportional to its molecular weight. All known molecular combinations and combining proportions are in accordance with the atomic doctrine. Decomposition by electrolysis affords

* A Treatise on the Forces which produce the Organisation of Plants. By John William Draper. (New York: Harper and Brothers, 1843.) + Pogg. Annalen for 1871 , No. 10. some evidence that the constituent parts of a molecule which are simultaneously separated are proportionate to atomic weights.

5. Atomic combining capacity. The modern doctrine of types and substitutions is solely based on the individuality of the atom, without which the whole fabric of typical structures must fall.

6. Isomerism. The fact that bodies containing the same elements, and in precisely the same proportions, exhibit different properties, has been thus far accounted for, only on the suppo.iion that atoms are differently arranged in each body. These differences in arrangement depend not only on the relative position of atoms, but also on the order as to time in whici they combins; for two or more atoms having such precedence over others as to cumbine first, may, by that means, furm a radical of such permanence as to play the part of an alom. A part from the question of radicals, we may ascertain the number of different bodies which can be formed from the same number of different atoms, by an application of the mathematical law of permutations.

7. Homorencity. The uniformity of structure and appearance of any eleinent or chemical combination of elements furnishes the most palpable proof of the identity in size and shape of those definite parts which we designate a; molecules. This homogeneity is retained under different degrees of pressure, thus making it apparent that molecules are not identical in structure, but that they approach and recede in precisely the same manner under the same conditions.

Finally.-The foregoing statement regarding the existence ot atoms which are indivisible and indestructible under the present order of things does not preclude the supposition that the atom may be a cluster of smaller particles held together by a powerful affinity, which, when counteracted, would leave them free to move within a given sphere. On this assumption it is highly probable that the relative position of such particles may modify the combining capacity of the atom. Moreover, the normal motion of such particles may determine not only the peculiarities of elemental spectra, but produce other effects not dependent on the amplitude of atomic oscillations, thus favouring the inference that the atom itself is a receptacle of force.

Samuel D. Tillman

\section{BLOOD.RELATIONSHIP *}

I PROPOSE in this memoir to deditce by fair reasoning from acknowledged facts a more definite notion than now exists of the meaning of the word "kinship." It is my aim to analyse and describe the complicated connection that binds an individual, hereditarily, to his parents and to his brothers and sisters, and, therefore, by an extension of similar links, to his more distant kinsfolk. I hope by these means to set forth the doctrines of heredity in a more orderly and explicit manner than is otherwise practicable.

From the well-known circumstance that an individual may transmit to his descendants ancestral qualities which he does not himself possess, we are assured that they could not have been altogether destroyed in him, but must have maintained their existence in a latent form. Therefore each individual may properly be conceived as consisting of two parts, one of which is latent and only known to us by its effects on his posterity, while the other is patent and constitutes the person manifest to our senses.

The adjacent, and, in a broad sense, separate lines of growth in which the patent and latent elements are situated, diverge from a common group and converge to a common contribution, because they were both evolved out of elements contained in a structureless ovum, and they jointly contribute the elements which form the structureless ova of their offspring.

The annexed diagram illustrates my meaning, and serves to show clearly that the span of each of the links in the general chain of heredity extends from one structureless stage to another, and not from person to person.

$$
\left.\begin{array}{c}
\begin{array}{c}
\text { Struciureless } \\
\text { elements in } \\
\text { Father }
\end{array}\{\ldots . . \text { Adult Father } \\
\text {............. }
\end{array}\right\} \begin{gathered}
\begin{array}{c}
\text { Structureless } \\
\text { elements in Father...... }
\end{array} \\
\text { offspring. }
\end{gathered}
$$

I will now proceed to consider the quality of the several relationships by which the above terms are connected together.

The observed facts of Reversion enable us to prove that the latent elements must be greatly more varied than those that are personal or patent. The arguments are as follows:-(I) There * Read before the Royal Society, June 13, by Francis Galton, F.R.S. 